\title{
LEARNING TO LIVE WITH MYCOTOXINS: AFLATOXIN-A CASE HISTORY
}

\author{
L. A. Goldblatt
}

Southern Regional Research Laboratory, Southern Region, Agricultural Research Service, US Department of Agriculture, P.O. Box 19687, New Orleans, Louisiana 70179, USA

\begin{abstract}
Experience with the aflatoxin problem may provide a useful guide in dealing with problems that may arise with other mycotoxins. Characteristics of mycotoxin situations are delineated. A multidisciplinary approach is needed in the following problem cases: ( $i$ ) Identification of the fungus responsible and isolation and characterization of the mycotoxin(s). (ii) Accurate analytical methodology for determination of the toxin and simple and rapid-though perhaps less accurate-methods for screening and control during processing. (iii) Incidence and scverity of contamination in various commodities and geographic areas. (iv) Environmental factors that contribute to development of the toxin: conditions of culture, harvesting, handling, transportation, storage and processing that minimize contamination.

Other related problems that are discussed are: (i) Genetic factors. (ii) Effects on various species of plants and animals and of possible synergists; precautions to be observed. (iii) Metabolic products and extent of biotransfer and acceptable tolerances in food and feed products. (iv) Marketing procedures; disposal of contaminated products; detoxification by removal or inactivation of the toxin by physical, chemical, or biological means.

Awareness of good operating practices, motivation of personnel to observe them, and adequate sampling and testing procedures are essential to assure that all foods and feeds are wholcsome. An expanded educational program and regulatory effort may be necessary. With continuous surveillance and vigilance of all, the consumer will receive better and safer products than ever before.
\end{abstract}

\section{INTRODUCTION}

When Professor Marcuse first suggested my participation in this symposium it occurred to us that we have now lived with the problem of aflatoxin for some ten years and that an assessment of our experience with aflatoxin might be useful in planning solutions to problems with other mycotoxins. I trust you will bear with me if I speak especially in the light of our experience in the United States. In any event, I believe it will be worthwhile first to take just a few minutes to supply some orientation or background.

Mycotoxins may be defined as toxic compounds produced by fungal contamination of foods and food raw materials. The toxicity syndromes resulting from the intake of such contaminated material by animals and man, 
usually by ingestion, have been termed mycotoxicoses. These are distinguished from mycoses, which involve a generalized invasion of living tissue by actively growing moulds. A mycotoxin is not itself a mould; it is a toxic material produced by a mould. The mould is a living organism; a mycotoxin is not.

Toxic factors of mould origin form a branch of study that has only recently aroused much interest. People born more than about fifty years ago were probably raised in the tradition that treated moulds as a regrettable nuisance that detracted from the appearance of foods or made them taste bad and caused some loss or spoilage. Interest in mould-induced damage to foods and feeds centred primarily on economic losses. Then, 25 to 30 years ago, studies on penicillin and other antibiotics showed that some mould metabolites were toxic to pathogenic bacteria and were able to save people and other animals from otherwise fatal infections. Because of the tremendous surge of interest, those brought up in the 1940s and 1950s may have grown to accept the view that moulds and mould metabolites are friendly things that help us counteract dangerous infections. The fact that many of these mould metabolites could not be used in practice because they were too dangerous for the host was obscured by the number and variety of the new wonder antibiotics. That these mould metabolites were effective only because they were poisonous to some other living things (bacteria) was also obscured. Penicillin is a mycotoxin for bacteria and lower forms of life, but not for man and most higher forms of life. However, it should perhaps be noted that penicillin causes allergic reactions in some individuals and that high doses have sometimes resulted in fatal anaphylactic shock.

Mycotoxicoses have been known for a very long time, although perhaps not by that name. Probably the first mycotoxicosis to have been recognized was ergotism which has been known to man for much of recorded history. Ergotism has its origin in ingestion of rye and other grains infested with the mould Claviceps purpurea. During feudal days in Europe, periodic outbreaks of the disease, known as 'St. Anthony's Fire' or the 'Holy Fire', resulted in thousands of deaths. Epidemics of ergotism are now rare but outbreaks occurred in Russia in 1926-27, in England in 1928 and in France as recently as 1951. Occasional isolated episodes are still reported. So, even though this disease is old and well known and its cause and prevention are also well known, the need for continuous surveillance and vigilance is evident. Also, although the hazard to the human food supply has largely been eliminated, contamination of certain types of pasture grasses by the fungus responsible continues to cause problems and is still of economic significance to livestock producers in some areas ${ }^{1}$. The point I want to make here is this. Despite the fact that we have had the problem of ergotism with us for so long, the problem has not been solved. All that we can say even now is that it is being controlled.

Another mycotoxicosis recognized to have seriously affected human populations directly is alimentary toxic aleukia (ATA). Incidence of the disease has been recorded in Russia from time to time at least as far back as the nineteenth century. Concurrent outbreaks in domestic animals have also been reported. The disease occurred with special severity in the war and postwar years of 1942-47, and Joffe ${ }^{2}$ has reported that in 1944, the peak year, more than 10 per cent of the population of certain districts was affected and 
many fatalities occurred. The disorder develops after eating over-wintered mouldy grain, chiefly millet but also wheat, rye, oats and buckwheat. Extensive studies carried out by Russian investigators indicated that the fungi primarily responsible belong to the genera Fusarium and Cladosporium. These fungi are very resistant to cold and require a low temperature to produce the toxin. Obviously, low temperature does not necessarily prevent elaboration of mycotoxins.

Bamburg et al. ${ }^{3}$, asserted that 'ATA must be listed as one of the most important human mycotoxicoses known'. Nevertheless, in 1962 , only 10 years ago. Forgacs ${ }^{4}$ aptly called the mycotoxicoses 'The Neglected Diseases' and wrote 'Of the innumerable diseases that affect man and domestic animals, the mycotoxicoses are perhaps the most unfamilar and least investigated.' In that same year, in a comprehensive review devoted mainly to veterinary mycotoxicoses, Forgacs and Carll ${ }^{5}$ noted that it is well recognized that fungi are among the most potent producers of biologically active organic compounds of great variety and wide spectra. However, they observed, 'Scientists tend to approach the causes of animal diseases through a process of elimination: if the causal agent is not found to be bacterial, viral, or nutritional, it is concluded to be chemical in nature. Even though this be true, the possibility that the source of such toxic chemicals may be fungal in origin is usually ignored.'

But this situation changed drastically with the developments relative to an apparently new disease which appeared in England in 1960 and was termed the 'turkey-X disease'. Reports of the death in the course of a few months of more than 100000 young turkeys on poultry farms dramatized the problem. Nor was the difficulty limited to turkeys as deaths of thousands of ducklings and young pheasants on nearby farms were reported. These reports of thousands of mortalities focused attention upon the practical problem, stimulated interest in the scientific community, and resulted in intensive investigations and a multidisciplinary approach on the part not only of veterinarians, but also of biologists, microbiologists, chemists, toxicologists, nutritionists and scientists in still other disciplines.

Six characteristics of mycotoxin situations have been delineated by Feuell ${ }^{6}$ :

(i) They frequently arise as veterinary problems whose true cause is not immediately identified.

(ii) The disorders (mycotoxicoses) are not transmissible from one animal to another, being neither infectious nor contagious.

(iii) Treatment with drugs or antibiotics usually has little effect on the course of the disease.

(iv) In field outbreaks the trouble is often seasonal, as particular sequences may favour toxin production by the mould.

(v) Careful study indicates association with a specific foodstuff, e.g. peanut meal, corn or rice.

(vi) Examination of the suspected foodstuff reveals signs of fungal activity. Such criteria are equally applicable to disorders in animal and man.

It is noteworthy how closely the aflatoxin problem exemplified the characteristic features of mycotoxin problems in general. It is interesting, in retrospect, to see how closely efforts directed to solution of the aflatoxin problem 
followed the pattern outlines by Forgacs and Carll Blount ${ }^{7}$ reported that it was soon generally agreed that no known microorganism had been isolated and that biological transmission was negative. Accordingly, there remained the possibility that the birds were being 'poisoned'. But all attempts to associate the disease with the presence of any of a quite large number of organic and inorganic poisons and poisonous plant materials were fruitless, even after the cause was traced to the presence of Brazilian groundnut (peanut) meal in the rations. Eventually, however, the cause was traced to a toxic factor produced by the very common mould Aspergillus flavus and that, as you all know, gave rise to the name Aflatoxin, from $A$ spergillus $F L A$ vus TOXIN.

\section{ANALYTICAL METHODOLOGY}

During this time a test for the toxin was developed using young ducklings. These were found to be particularly susceptible and to be especially suitable for evaluation of toxicity based upon death or the appearance of characteristic histological lesions in the liver. The test was also used to effectively monitor the extraction and concentration of the toxin through classical procedures of the organic chemist. It was then noted that toxic extracts illuminated with ultraviolet light emitted a characteristic bright-blue fluorescence. Further, the amount of fluorescent material, as estimated visually, generally afforded a convenient guide to the toxicity of the sample. Thus the basis for routine chemical assay of the toxin was provided for the first time.

The importance of adequate analytical methodology should be stressed as it is an aspect so often neglected until it becomes abundantly clear that it is essential for further progress. I would like to elaborate on the subject of analytical methodology for awhile. Ten years ago the elapsed time for a single chemical analysis for aflatoxin was nearly three days. That doesn't mean that it took three man-days to carry out an analysis; but three days elapsed from the time an analysis was begun to the time a value was obtained. That was for a single aflatoxin and the method was relatively insensitive and highly subjective. Since then, methodology has been improved to increase sensitivity, accuracy, reproducibility and objectivity, and to decrease time. Now, in only a few hours, many commodities can be assayed for several aflatoxins with a sensitivity of less than $1 \mathrm{ppb}\left(1 \mu \mathrm{g} \mathrm{kg}^{-1}\right)$ and with a reproducibility of about $\pm 10-20$ per cent. This has resulted from numerous improvements introduced by many investigators and from extensive collaborative studies to evaluate analytical methodology.

In the United States today we have methods officially recognized by such organizations as the Association of Official Analytical Chemists, the American Oil Chemists' Society and the American Association of Cereal Chemists for the determination of aflatoxin in such products as peanuts, cottonseed, green coffee and corn. All these methods must be subjected to collaborative study and statistical evaluation before they are accepted. As you doubtless know, there is now under way an international check sample series program for the determination of aflatoxin in peanut products. Such collaborative tests are very worthwhile and may well be introduced for other important mycotoxins that may be recognized. Also, simple chemical confirmatory tests have been developed. I think it is fair to say that the biggest problem 
of analysis for aflatoxins today is that of securing a suitable representative sample. And that problem has still not been solved satisfactorily.

But it should be noted that there is still no single quantitative analytical method suitable for the determination of aflatoxin in all commodities. Thus a method that is quite satisfactory for peanuts is not suitable for cottonseed products and that, in turn, is not suitable for eggs, for alfalfa, or for mixed animal feeds. Although no method has been developed for determining aflatoxins in diverse commodities, there appears to be an increasing effort devoted to simultaneous determination of several mycotoxins in the same commodity-for example, aflatoxin, ochratoxin and zearlalenone in corn.

Also important to these improvements in methodology has been the availability of recognized aflatoxin standards. When the need for such standards became evident in the middle 1960 s, and none were available commercially, we at the Southern Regional Research Laboratory undertook to distribute solutions of the four common aflatoxins recognized at that time, $B_{1}, B_{2}, G_{1}$ and $G_{2}$ as standards to laboratories having need for them. Availability of such standards has been of great value in connection with control of aflatoxin problems and potential problems. I understand that these standards have been used for the analysis of more than a million samples of peanut products in the United States alone. Aflatoxin standards are now available from commercial sources. As a result of this experience the need will probably be recognized for the availability of standards of other important mycotoxins, and hopefully provision will be made at an early stage to supply them.

\section{ISOLATION AND CHARACTERIZATION}

Research has produced a wealth of information about aflatoxin in the past dozen years. At this time (1972) at least twelve closely related compounds designated aflatoxins have been isolated and characterized and several have been synthesized. The isolation, identification and characterization of these complex compounds in the short time that has elapsed since their discovery must be regarded as one of the major achievements in recent times in the chemistry of natural products.

The structures of these aflatoxins are shown in Figure 1, but I shall not discuss their determination. Suffice it to say that although considerable information was obtained by classical procedures of the organic chemist, elucidation of their structures relied heavily upon recently developed physical methods and interpretation of ultraviolet, infrared, nuclear magnetic resonance and mass spectra. Doubtless these same procedures will be used in the elucidation of structures of the new mycotoxins. The latest addition to the family of aflatoxins, $\mathrm{P}_{1}$, a phenol, is the principal urinary metabolite of aflatoxin $B_{1}$ in monkeys, but it has not been identified from mould cultures. I believe that most of us who were schooled as organic chemists, as I was, would accept as elementary, and without question, the value of the determination of the chemical structures of mycotoxins that may be identified, but others may require justification. In the case of the aflatoxins, determination of structures was achieved very rapidly, and knowledge of the structures has 


\section{A. GOLDBLATT}
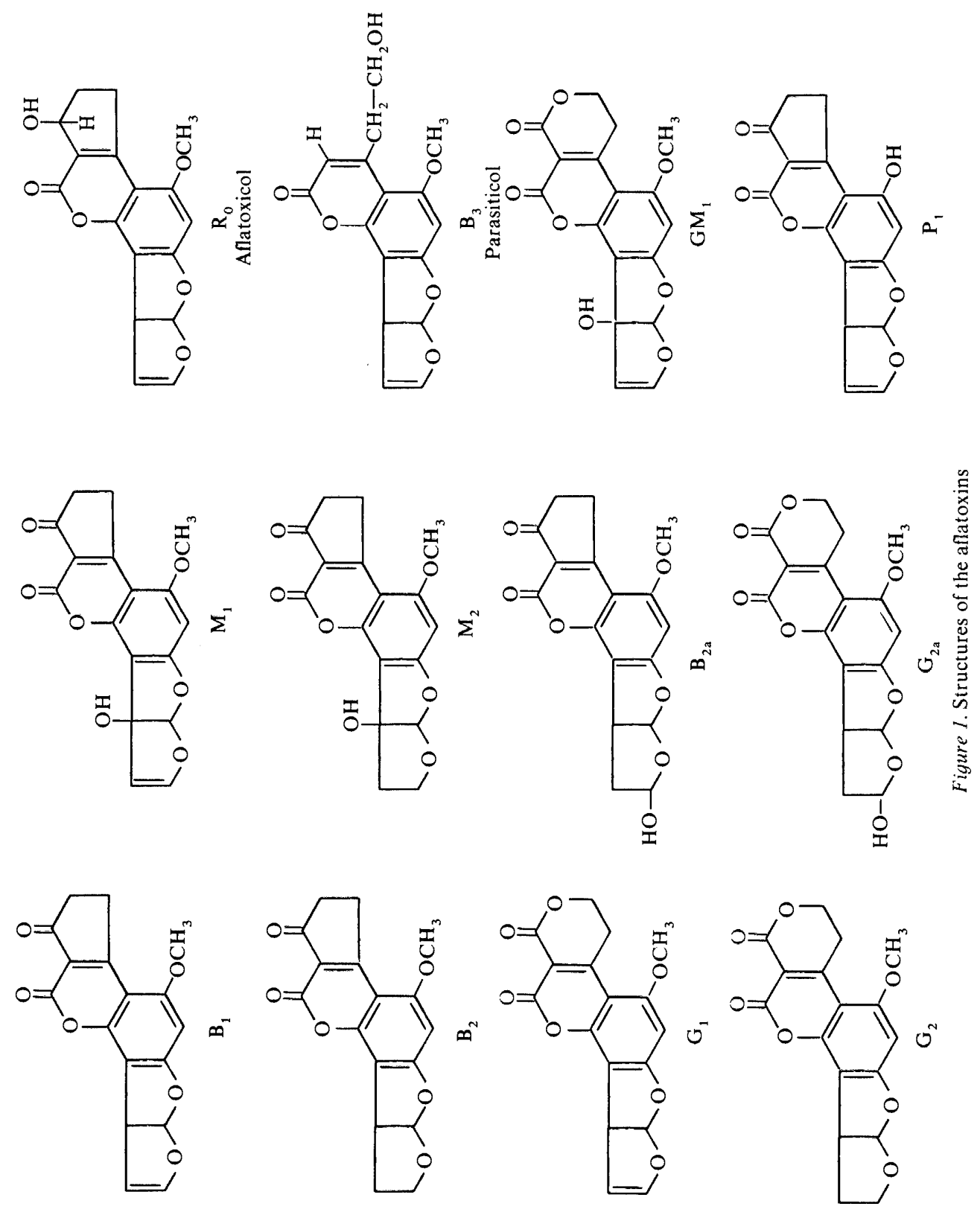
proved to be invaluable in studies on determination of metabolic products and as a guide in the development of practical methods for their removal or inactivation. The experience with aflatoxin fully supports the intuitive judgment of the organic chemist of the value of structure determination and its relevance, and should lend support for analogous efforts with other mycotoxins.

\section{BIOLOGICAL EFFECTS}

Much effort has been devoted to determination of the biological effects of the aflatoxins on various plant and animal species, to ascertain 'no-effect' levels of aflatoxins and to determine their metabolic fate. The toxic properties of the aflatoxins manifest themselves differently depending upon the test system, the dose and the duration of exposure. Aflatoxin $B_{1}$ has been investigated far more thoroughly than any of the others. It is generally the most plentiful and it is acutely toxic to most animal species. Some of the other aflatoxins approach $\mathrm{B}_{1}$ in toxicity but others are relatively non-toxic. For example, the toxicity of aflatoxin $\mathrm{B}_{2 \mathrm{a}}$ for ducklings is certainly less than one hundredth that of $B_{1}$.

Aflatoxin $B_{1}$ has been found to be a powerful carcinogen for certain animal species. This has special significance in the United States where the so-called Delaney clause in the Federal Food, Drug and Cosmetics Act, dealing specifically with the safety of food additives, provides that '. . no additive shall be deemed to be safe if it is found to induce cancer when ingested by man or animal, or if it is found, after tests which are appropriate for the evaluation of the safety of food additives, to induce cancer in man or animal ... ${ }^{8}$. Aflatoxins, and presumably other mycotoxins, are considered to be unintentional foöd additives and so are governed by the Act. Accordingly, in the United States, no acceptable tolerance can be set for aflatoxin, inasmuch as it is a known carcinogen. This is not the case in most countries, and the Protein Advisory Group of the United Nations System in 1966 settled upon a maximum level of $30 \mathrm{ppb}\left(\mathrm{g} \mathrm{kg}^{-1}\right)$ for foodstuffs. This level was evolved on the basis of feeding experiments in monkeys, where the "no effect' level was found to be $300 \mathrm{ppb}$, and application of a safety factor. The Protein Advisory Group would have preferred to impose a lower level in order to provide a wider margin of safety. However, it was believed there was an even more urgent need to provide extra protein in some parts of the world in order to prevent malnutrition and starvation. The hope was expressed that with further improvements in agricultural practice it would become feasible to insist on lower levels of aflatoxins in food and remain confident that adequate supplies would remain available. This level, which is being reviewed annually, was reaffirmed in later years. Clearly it was concluded that it is better to run the risk of cancer from aflatoxin in old age than to die in early youth from a lack of protein.

Aflatoxins have other genetic effects also. Aflatoxin $B_{1}$ is mutagenic and teratogenic as well as carcinogenic ${ }^{9}$. But another dimension was added when it was reported that an interaction exists between aflatoxins and cyclopropenoid fatty acids fed to rainbow trout ${ }^{10}$. Certain cyclopropenoid fatty acids - malvalic and sterculic acid-are constituents of the lipids of cotton- 


\section{A GOLDBLATT}

seed and the seeds of other plants of the order malvales. Addition of cyclopropenoids to the diet of rainbow trout promoted early development of tumours and increased their incidence and growth rate over positive controls. Also, it has been shown that two mycotoxins may have synergistic effects in host animals. A synergistic effect on tumour incidence in trout has been demonstrated between aflatoxins $B_{1}$ and $B_{2}{ }^{11}$ and on toxicity symptoms in rats, not attributable to either compound alone, between aflatoxin $B_{1}$ and rubratoxin $\mathbf{B}^{12}$. Thus a stated response can be subject to appreciable alteration by the presence of other factors, and an apparent 'no effect' level is valid only for a specific experimental protocol. This will presumably be given due consideration in evaluating the biological effects of the new mycotoxins.

In the United States the Delaney clause applies to animal feeds as well as to foods for humans, except that there is an escape hatch. The Act carries the further provision that '... this proviso shall not apply with respect to the use of a substance as an ingredient of food for animals which are raised for food production, if the Secretary finds (1) that, under the conditions of use and feeding specified in proposed labelling and reasonably certain to be followed in practice, such additive will not adversely affect the animals for which such feed is intended, and (2) that no residue of the additive will be found (by methods of examination prescribed or approved by the Secretary) ...... in any edible portion of such animal after slaughter or in any food yielded by or derived from the living animal'.

Accordingly, in the United States, as in other countries, much effort has been devoted to determination of no-effect, or tolerance, levels and to investigation of possible adverse effects of aflatoxins on farm animals and of possible transmission of toxins into edible animal products or tissues. Inclusion of aflatoxins at high-dose levels in feed given to cattle, swine and poultry inhibits growth and decreases feed efficiency. And economically this reduction in growth may result in much greater losses than those readily apparent when many animals sicken or die. Even a one per cent reduction in feed efficiency can obviously result in very large economic losses.

Sensitivity to aflatoxin decreases with age in all species studied and there may also be sex differences. Striking differences in susceptibility may be observed in different breeds or strains of certain animal species. Thus New Hampshire chicks and turkey poults were found to be highly susceptible, in contrast to the resistance of Barred Rock chickens and guinea fowl. However, it has been reported that in contrast to the high degree of susceptibility of New Hampshire chicks, the resistance of New Hampshire-White Leghorn hybrids to aflatoxin is impressive, suggesting that susceptibility may be under genetic control' ${ }^{13}$. If so, the possibility exists for reducing losses from aflatoxin intoxication, and possibly from other mycotoxicoses, by genetic modification of the animal species.

Another important question with aflatoxin, as with other mycotoxins, is that of possible transmission into animal products such as tissues, milk and eggs. It has been well established that dairy cows fed aflatoxin will secrete small amounts of a toxic factor in their milk. The situation with respect to transmission into eggs by laying hens is less well established. A number of experiments have been conducted to investigate the deposition of aflatoxin or toxic metabolites into edible animal tissue. Early reports in the literature 
did not reveal the presence of aflatoxins or other toxic metabolites but more recent reports, especially those of Dr Krogh who is our Chairman this morning and is to discuss the subject of aflatoxin residues in swine organs and carcasses this afternoon, do indeed indicate that such transmission occurs. Research is currently underway to determine which levels of aflatoxins in animal feeds will result in negative or negligible transmission of toxin into edible animal tissues. Such determination is obviously of great importance in the United States in view of the provisions of the Delaney clause for animal feeds.

\section{INCIDENCE}

Let us next consider the incidence of mycotoxin contamination. In a very early phase of our work on aflatoxins we conducted a statistically designed survey of the incidence and severity of aflatoxin contamination in stocks of peanuts held by the Department throughout the United States, something like 200000 tons. The sample plan included sampling warehouses in States in all of the peanut-producing areas of the United States, and different types and grades of peanuts, including runner, Spanish and Virginia types, and Damaged Kernels as well as Sound Mature Kernels. The survey indicated that aflatoxin may be found in peanuts in all of the important peanutproducing areas of the United States. By defining the scope of the problem, the survey was an important factor in developing the Department's program for the orderly marketing of the 1964 peanut crop. This strict but effective marketing program designed to keep contaminated peanuts out of food channels worked out remarkably well. An insurance plan was developed designed to eliminate, or minimize, possible losses to producers, shellers, or processors and was modified in other ways during the intervening years, as indicated by experience. The major provisions of the Program at present include:

(i) Inspection of all peanuts when delivered by producers with removal from food trade channels of lower quality lots.

(ii) Sampling by Government inspectors for aflatoxin of all lots of raw, shelled peanuts, with analysis of all disputed lots by Government laboratories.

(iii) Diversion from food channels of all lots of raw, shelled peanuts that contain aflatoxins above a specified level.

(iv) Indemnification of shellers on lots diverted to crushing because of aflatoxin.

The indemnification to shellers is paid for by the insurance program. The cost of the insurance for the 1972 crop has been set at $\$ 2.25$ per net ton of farmers stock peanuts with an additional 30 cents per ton for administrative expenses, for a total of $\$ 2.55$ per ton.

The National Peanut Council of the United States adopted a Voluntary Code of Good Practices for Purchasing, Handling, Storage, Processing and Testing of Peanuts ${ }^{14}$. Originally adopted in 1964 and revised and updated with experience at least once each year the Code is now in its ninth edition. The Code emphasizes the need for repeated analysis for aflatoxin at various stages of handling and processing. 
An excellent working relationship was established between the Department of Agriculture, the peanut industry and the Food and Drug Administration. I would like to note here that Dr Campbell, who is the next speaker in this symposium, was an important architect of that relationship. It has been cited as an outstanding example of co-operation between industry and government in the solution of an important problem and, paradoxical as it may seem, because of aflatoxin, the American public is now getting higher quality peanuts and peanut products than ever before. It is suggested that this pattern may serve as a model for future co-operation between Government groups and other commodity groups that may be affected, not only for aflatoxins but also for other important mycotoxins that may be encountered.

\section{Prevention}

\section{CONTROL}

What can be done in the way of control of mycotoxins? Unquestionably the best approach is prevention, and the first step is recognition and awareness that a problem and a threat exist. Again, it appears that our experience with aflatoxin may serve as a guide for problems with other mycotoxins. It was recognized that every agricultural commodity is open to fungal attack under adverse conditions if the appropriate species are present. However, in the case of aflatoxin, it was generally felt that prevention of production of the mycotoxin was essentially a problem of proper storage, and that drying a crop rapidly to below the point at which the fungus would grow would provide an effective means of control. For some time it was felt that contamination with aflatoxin was due primarily to careless, or at least faulty, storage practice, or perhaps to inadequate care during harvesting. The scarcity of reports of aflatoxin contamination in freshly dug peanuts tended to confirm that view. However, it is now known that aflatoxin may be found in certain commodities while growing in the field. Certainly that is the case for the three commodities with which our laboratory has been most concerned: peanuts, cottonseed and corn.

In the case of peanuts, there has long been a record of injury to swine that have been turned loose to feed on peanuts remaining in the ground after harvest, and there are now many reports of aflatoxin contamination of freshly dug peanuts.

In the case of cottonseed, there are some areas in the United States in which aflatoxin contamination may readily be observed in seed in the mature bolls on the lower part of a cotton plant while the bolls on the upper part are still developing. This is especially the case where the pink boll-worm is prevalent. The exit holes left by the boll-worm larvae supply important avenues for entry for $A$. flavus, as well as other fungi, and this illustrates the importance of good insect control for control of production of mycotoxins. However, presence of the boll-worm is not a necessary condition for presence of aflatoxin in cottonseed in the field. There are other important contributory factors and it has been concluded that, at least in California, 'the aflatoxin problem of cottonseed is the result of seed infection that occurs in the field. It does not appear to be a problem that originated in storage, nor does it appear to be aggravated there' ${ }^{15}$. Please note that this report refers specifically 
to cottonseed and to California. We know that the problem of aflatoxins with other commodities certainly may be aggravated by improper storage, but I wanted to call this report to your attention as it marks such a complete reversal from the common view that was held previously.

A more recent important development is the recognition of the presence of aflatoxin in corn while it is growing in open fields. There is considerable damage by insects and birds to growing corn, which facilitates invasion by $A$. flavus. Contamination with aflatoxin in such instances is not surprising, but aflatoxin may also be found in apparently undamaged ears of corn growing in the field. Fortunately, biologically significant amounts of aflatoxins occur infrequently in samples taken at harvest. The possibility that other recognized mycotoxins may also be found in crops at harvest must be recognized.

A major problem is motivation of untrained personnel at all stages of culture, harvest, transportation, storage and processing. The Agricultural Research Service of the US Department of Agriculture has issued a special report entitled 'Preventing Mold-Caused Toxins in Farm Commodities' ${ }^{16}$ and copies are available on request. Note that this refers to 'Mold-Caused Toxins', not just to aflatoxins. The implication obviously is that the guidelines for aflatoxin can also serve for other mycotoxins. In this report the importance of good farm management practices is emphasized, and it is noted that mould prevention should begin with proper planting and growing of a crop. Harvesting at maturity is generally recommended and it is pointed out that it is the farmer's responsibility to take the proper measures so that commodities are neither damaged by mould in the field, nor harvested and stored in a condition favourable to moulding before they reach marketing channels.

\section{Diversion}

In this report it is noted that special attention should be given to detecting lots that contain aflatoxin and diverting them from food and feed channels as early as possible in the marketing process. Early detection and diversion of small consignments of contaminated materials may prevent contamination of much larger supplies. However, to achieve this, rapid methods of detection are required. Until fairly recently, primary emphasis upon improved analytical methodology for aflatoxins was to increase sensitivity and accuracy, with relatively little emphasis on decreased time, especially if it meant any sacrifice in sensitivity, accuracy or reproducibility. Recently, however, it has come to be recognized that a relatively insensitive method can be extremely useful if it is also very rapid.

Dickens and Welty ${ }^{17}$ noted several years ago that there is a high correlation between aflatoxin content and presence of Aspergillus flavus mould readily observable in damaged peanut kernels when viewed under low magnification. That is, if $A$. flavus mould can be seen in any of the Damaged Kernels in a lot that is examined there is a high probability that a high level of aflatoxin will be found in that lot of peanuts. Conversely if no A. flavus mould can be seen in the Damaged Kernels, there is a low probability of finding aflatoxin in that lot. And even if aflatoxin is found where there is no observable $A$. flavus mould in the Damaged Kernels, the aflatoxin is usually present at a much lower level. The commercial grading system for peanuts in the United States-and the grade provides the basis for the price to be 
paid - calls for an actual count of the number of Damaged Kernels of peanuts in the sample that is graded. As a result of Dickens and Welty's finding, another step was introduced into the inspection system - examination by the inspectors of the Damaged Kernels for $A$. flavus mould. Each inspector is given a folder with two sets of coloured photographs, about $20 \mathrm{~cm}$ by $30 \mathrm{~cm}$, that shows him what to look for and what not to look for. These are illustrated in Figure 2. This additional operation is said to take less than a minute for each sample, but it has been extremely valuable to the peanut industry in the United States in diverting contaminated lots of peanuts from the food supply chain.

Unfortunately, there is no similar procedure available for many other commodities. However, a simple and rapid chemical procedure was recently developed for detecting aflatoxin in cottonseed ${ }^{18}$. This test is sensitive to about 5 to $10 \mathrm{ppb}$, and it can be completed in 15 minutes or even less. The test is semiquantitative in that one can distinguish, for example, between 10 , 50 and $150 \mathrm{ppb}$ but not between 15 and $20 \mathrm{ppb}$ or between 50,60 and $70 \mathrm{ppb}$. This rapid procedure has been found to be very useful in detecting lots of contaminated cottonseed before they are unloaded from trucks so they could be diverted for separate processing and it has been used on a large scale for that purpose this past year. But the procedure has also been used with various other agricultural commodities, including peanuts, corn and tree nuts such as pecans and pistachio nuts, and it has been tested successfully with various other oilseeds and grains ${ }^{19}$. For some of these commodities the method originally developed had to be modified by inclusion of an additional clean-up step that extended the time for a determination to about 20 minutes. Such rapid and simple procedures are useful not only for segregation of contaminated lots of materials but also for control during processing. Also, this test is very much less expensive than are the usual quantitative methodsno small matter in view of the very large number of tests that need to be made for adequate control. This aspect of analytical methodology has been rather slighted in the past, but perhaps developments in control of the newer mycotoxins may benefit from these experiences with aflatoxin.

\section{Genetic approaches}

Genetic approaches that may result in resistance to elaboration of aflatoxin are under investigation. Development of commercially acceptable varieties that would resist toxin-producing moulds or completely inhibit production of toxin would be an ideal solution. The report that impermeable seed coat cottonseed-so-called 'hard seed'-have less tendency to allow A. flavus to grow and produce aflatoxins than do seed without this 'hard coat' trait, indicates that possibility exists for mould invasion and hence production of aflatoxin in cottonseed to be controlled by genetic means ${ }^{20}$. A varietal difference in the production of aflatoxins in pcanuts inoculated with a toxigenic strain of $A$. flavus has been reported, but this has not been confirmed $^{21}$. Research directed towards identifying peanut lines with resistance to toxin-producing moulds is continuing, and it appears to show some promise, but this is a long-term approach and no lines have yet been released. Results of these efforts at genetic control of aflatoxin will surely guide analogous efforts with other mycotoxins. 


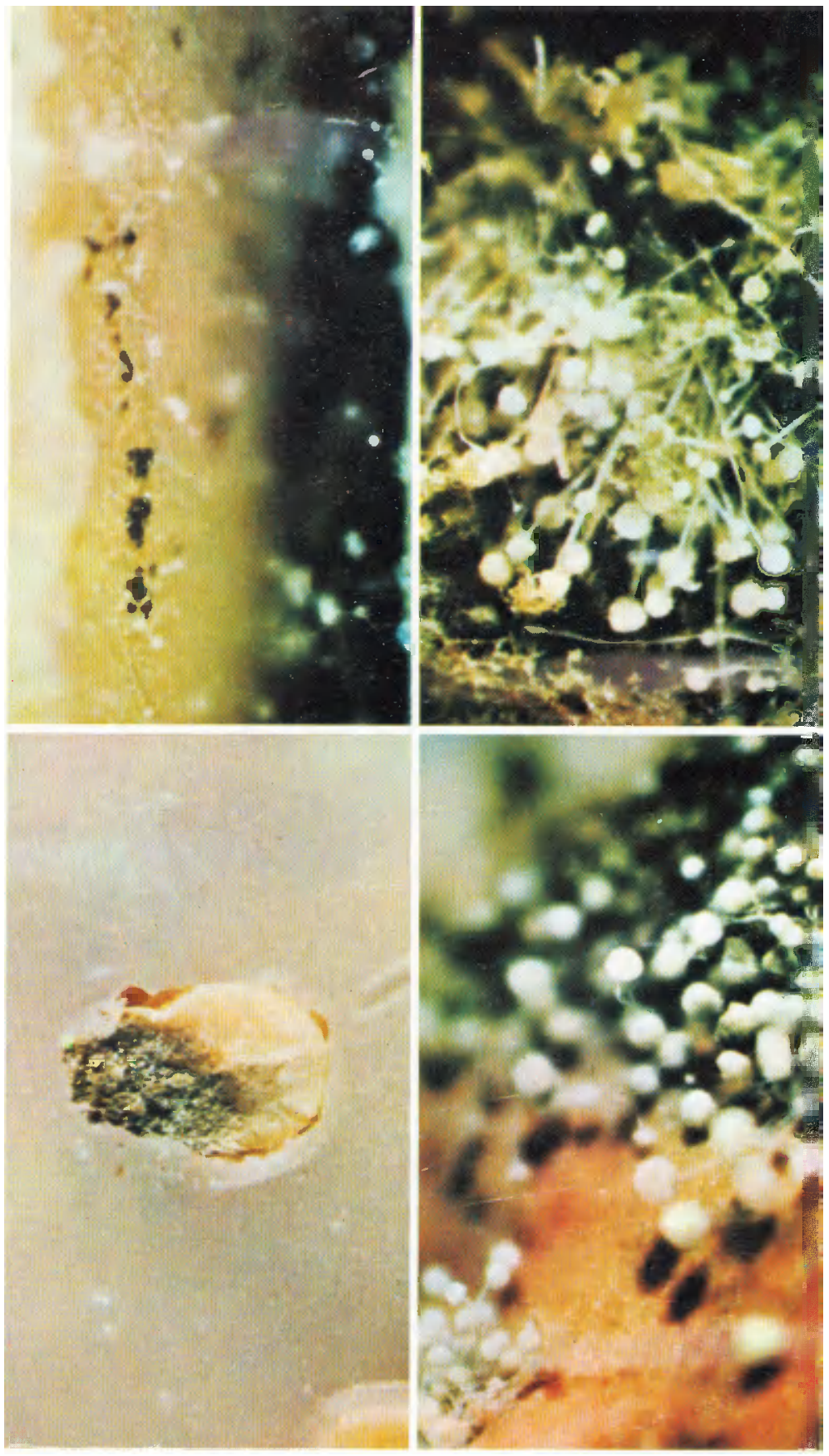

물 ए ए ह प्र क

ऽ근

ड

है

三号艺 ธง

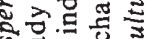
₹ 它总导 전응

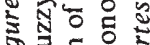
स्य 苞 홓 둔 $\circ$ क्ष Ð્屯 즐 둔 무ㅇㅝㅛ 로응 $\geq \mathcal{0}$ 氖告 क ธ 튼 近 $\lceil$ 동 क 㟒点。 응 


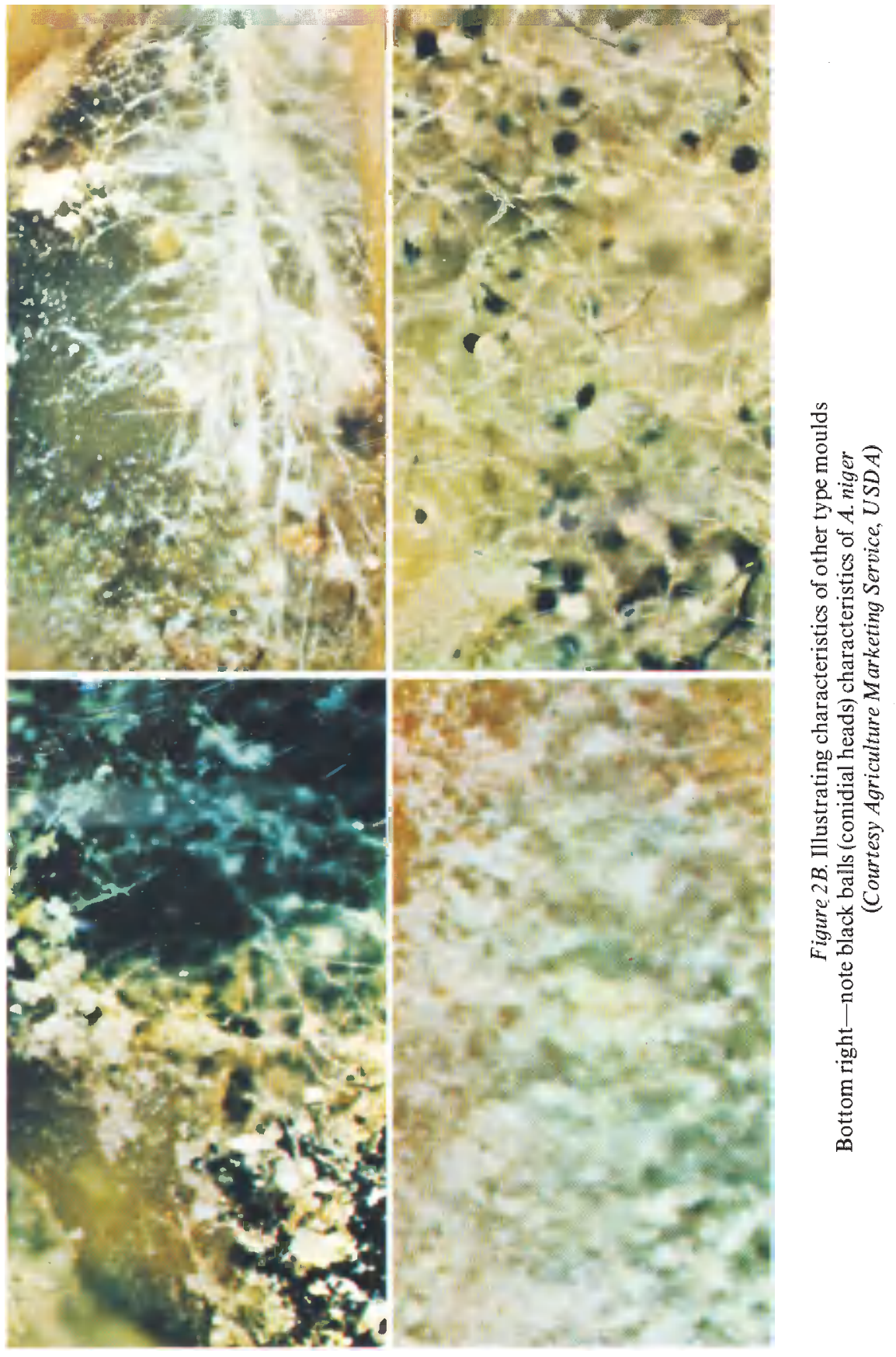




\section{Antifungal agents}

The use of antifungal agents to control fungal infestation has been the subject of much study, but until recently there has not appeared to be any large-scale application. Recently, however, it was reported that a mixture of acetic and propionic acids was successful in preventing the development of aflatoxin in high-moisture corn. The process is now in use on a relatively large scale in the United States and Canada.

\section{Detoxification}

Contamination with aflatoxin can occur despite the most strenuous efforts at prevention and, as indicated carlier, contamination can occur in the field before harvest. So detoxification must be considered, fully recognizing that it is to be applied only if preventive measures have failed and not as an alternative to good cultural and storage practice. The detoxification of commodities contaminated with aflatoxin will not be discussed in detail. Many approaches have been investigated. Procedures that have been successful range from mechanical removal of contaminated material by hand and by electronic or pneumatic sorting, to extraction with solvents, to various chemical treatments. Each of these processes has advantage in specific applications and is currently in use; for example, in the mechanical sorting of peanuts and Brazil nuts, in the removal of aflatoxins from crude oils by refining with aqueous alkali, in the destruction of aflatoxin in cottonseed meal by ammonia under heat and pressure and in copra by hot calcium hydroxide. Presumably each commodity, each mycotoxin, and perhaps each location will present its special problems and solutions.

\section{AWARENESS OF MYCOTOXICOSES}

The need for motivation of untrained personnel was mentioned previously. An important factor here is simple unawareness. Fortunately, despite Forgacs and Carll's characterization, only ten years ago, of the mycotoxicoses as the neglected diseases, this is no longer the case - at least not by the scientific community as a few examples will indicate. As you may know, there was an outbreak in the United States in 1970 of the Southern Corn Blight. That disease is incited by the fungal pathogen Helminthosporium maydis and the damage results when the fungus invades corn-plant tissue in the field. According to a report given at a meeting held in October of that same year, 1970 , 'one of the first considerations when corn fields were invaded with Southern Corn Blight was whether the mould might form toxic compounds on corn harmful to man and animals' ${ }^{22}$. Contrast this with Forgacs' realistic appraisal of the situation before aflatoxin.

Another indication of the change may be noted. The frequency of multiple cases of deaths from cancer in the same house has given rise to the hypothesis of the existence of 'cancer houses', which has been under discussion for many years. Recently there was a report of multiple cases of leukemia associated with one house ${ }^{23}$. Four cases of leukemia associated with the same house occurred over a ten-year period. Radiation surveys of the house and its surroundings revealed no abnormalities. It was concluded that the occurrence 


\section{A. GOLDBLATT}

of multiple cases of leukemia in a single house is a rare event, that the significance of such events is hard to assess, but that their possible importance warrants close investigation. This report promptly led to a Letter to the Editor $^{24}$ with the suggestion that a study of the mould population of the house be made. Awareness of the potential problem of toxicoses induced by moulds is a valuable spin-off from aflatoxin research.

Some recent reports have dealt with isolation of toxin-producing fungi or mycotoxins from fungi commonly associated with foods or feeds discovered in the course of intentional searches for previously unrecognized fungal toxins. A good example is provided by the ochratoxins. Van der Merwe et al. ${ }^{25}$, in 1965 reported the isolation and characterization of a new mycotoxin, 'Ochratoxin A', from cultures of Aspergillus ochraceous that were isolated from South African cereal and legume crops. Note that it was the organism, not the toxin, that was isolated from the grain. Subsequently, in 1969, Shotwell et $a l^{26}$, of the Northern Regional Research Laboratory in the United States reported for the first time the natural occurrence of ochratoxin $\mathrm{A}$ in corn. And today, in this symposium, our Chairman this morning is the author of a paper on the natural occurrence of ochratoxin $A$ in cereals associated with an outbreak of swine nephropathy and the co-author of a paper on ochratoxin residues in bacon pigs. Such studies contrast with most previous studies in which mycotoxins were discovered retrospectively after episodes of human or animal toxicoses.

Another example is sterigmatocystin. Investigation of the metabolites of Aspergillus versicolor led to the isolation and characterization of sterigmatocystin which is structurally related to the aflatoxins ${ }^{27}$. Sterigmatocystin is much less toxic and carcinogenic than is aflatoxin $\mathrm{B}_{1}$, but Holzapfel et al. ${ }^{28}$ have found that three strains- $A$. nidulans, $A$. flavus and $A$. rugulosusgrown on cornmeal produce large amounts of sterigmatocystin, up to $1.2 \mathrm{gm} \mathrm{kg}^{-1}$. That is about a thousand times the amount of aflatoxin that may be anticipated. Accordingly, they warn that, based on concentration, sterigmatocystin may prove to be a more formidable danger than aflatoxin.

However, the awareness pertains to the scientific community. How much awareness is there on the part of the producer, the handler, the processor and even management? The problem now may be not so much a lack of technical information as ineffective dissemination of cxisting knowledge. New approaches may have to be sought for disseminating technical knowledge to appropriate personnel.

\section{CONCLUSION}

So let us sum up the situation. Consideration of our experience with aflatoxin indicates that it can be of material assistance in dealing with other mycotoxins. Features that characterize mycotoxin situations have been delineated. The need for a multidisciplinary approach, for identification of the fungus responsible, for characterization of the toxins, and for determination of environmental conditions that contribute to their elaboration are clearly evident. Determination of biological effects, no-effect levels, possible synergists, and possible transmissions into animal products is needed. Surveys to determine incidence and severity of contamination are indicated. 
Development of accurate analytical methodology is essential and so also is simple and rapid methodology suitable for screening and segregation of contaminated lots of commodities early in the marketing chain and for control during processing. Marketing procedures designed to remove contaminated materials from food and feed channels need to be developed, possibly including insurance programs, and methods should be devised to remove or destroy contamination. Although aflatoxin has focused attention on mycotoxins, an expanded educational and regulatory program may be necessary.

Fungi are ubiquitous and formation of mycotoxins is not restricted to any genus, family, order or class of fungi. Every known plant and animal product is susceptible to fungal attack under the appropriate conditions. Mycotoxicoses are no longer the neglected diseases. There now appears to be the same kind of scientific interest in mycotoxins as there was some 60 years ago in vitamins. At that time we began to be aware of illnesses caused by the absence from the diet of trace amounts of unrecognized materials that were called vitamins. Now we are dealing with illnesses that are caused by the presence in the diet of trace amounts of previously unrecognized materials that are called mycotoxins. Mycotoxicoses have been known for centuries. Despite this we have succeeded only in controlling-not eradicating-even the best known mycotoxicosis, ergotism. Perfect safety may be the unattainable dream; we may have to learn to live with some acceptable level of risk. But with a new awareness, with continuous surveillance and vigilance, the consumer will receive better and safer products than ever before.

\section{REFERENCES}

1 G. N. Wogan, Food-Borne Infections and Intoxicants, p. 395, (ed. H. Riemann), Academic Press (1969).

2 A. Z. Joffe, Mycotoxins in Foodstuffs, (cd. G. N. Wogan), MIT Press, Cambridge (1965).

3 J. R. Bamburg, F. M. Strong and E. B. Smalley, J. Agr. Food Chem., 17, (3) 443 (1969).

4 J. Forgacs, Feedstuffs, 34, (18) 124 (1962).

5 J. Forgacs and W. T. Carll, Adv. Vet. Sci., 7, 273 (1962).

${ }^{6}$ A. J. Feuell, Aflatoxin-Scientific Background, Control, and Implications, p. 188 (ed. L. A. Goldblatt), Academic Press (1969).

7 W. P. Blount, Turkeys (J. Brit. Turkey Fed.), 9, (2) 52 (1961).

8 J. H. Weisburger and E. K. Weisburger, Food Cosmet. Toxicol., 6, 235 (1968).

9 M. S. Legator, J. Am. Vet. Med. Assoc, 155, (12) 1928 (1969).

10 D. J. Lee, J. H. Wales, J. L. Ayres and R. O. Sinnhuber, Cancer Res., 28, (11) 2312 (1968).

11 J. L. Ayres, D. J. Lee, J. H. Wales and R. O. Sinnhuber, J. Natl. Cancer Inst., 46, (3) 561 (1971).

12 G. S. Fdwards and G. N. Wogan, Federation Proc., 27. 552 (1968).

13 A. C. Keyl and A. N. Booth, J. Am. Oil Chemists' Soc., 48, 603 (1971).

14 National Peanut Council, McLean, Va. 22101, Voluntary Code of Good Practices (1971).

15 L. J. Ashworth, Proc. 20th Oilseed Processing Clinic, ARS 72-93, 33 US Dept. of Agr., New Orleans, La. 70179 (1971).

16 ARS 20-16, 10 p. US Agricultural Research Service, US Department of Agriculture (1968).

17 J. W. Dickens and R. E. Welty, Mycopathol. Mycol. Appl., 37, 65 (1969).

18 A. F. Cucullu, W. A. Pons, Jr. and L. A. Goldblatt, J. Assoc. Offic. Anal. Chemists, 55, (5) 1114 (1972).

19 W. A. Pons. Jr., A. F. Cucullu, A. O. Franz, Jr., L. S. Lee and L. A. Goldblatt, J. Assoc. Offic. Anal. Chemists, 56, (4) 803 (1973).

20 R. Y. Mayne, G. A. Harper, A. O. Franz, Jr., L. S. Lee and L. A. Goldblatt, Crop Sci., 9, 147 (1969)

21 B. Doupnik, Jr., Phytopathology, 59, 1554 (1969).

22 C. W. Hesseltine, J. J. Ellis and O. L. Shotwell, J. Agr. Food Chem., 19(4) 707 (1971). 


\section{A. GOLDBLATT}

${ }^{23}$ P. McPhedran and C. W. Heath, Jr., J. Am. Med. Assoc., 209(13), 2021 (1969).

24 B. M. Wray, J. Am. Med. Assoc,, 210(10). 1924 (1969).

25 K. J. Van der Merwe, P. S. Steyn, L. Fouric, De B. Scott and J. J. Theron, Nature, 205, (4976) $1112(1965)$.

26 O. Shotwell, C. W. Hesseltine and M. L. Goulden, Appl. Microbiol., 17, 765 (1969).

${ }^{27}$ E. Bullock, J. C. Roberts and J. G. Underwood, J. Chem. Soc., 4179 (1962).

${ }^{28}$ C. W. Holzapfel, I. F. H. Purchase, P. S. Steyn and L. Gorrins, S. African Med. J., 40, 1100 (1966). 